\title{
Coping strategies as mediator variables between explanatory styles and depressive symptoms
}

\author{
Pilar Sanjuan ${ }^{1 *}$ and Alejandro Magallares ${ }^{2}$ \\ 1 School of Psychology. Personality, Evaluation and Psychological Treatment Department, Spanish Open University (UNED) \\ 2 School of Psychology. Social Psychology Department, Spanish Open University (UNED)
}

\begin{abstract}
Título: Estrategias de afrontamiento como variables mediadoras entre estilos explicativos y sintomas depresivos.

Resumen: El principal objetivo de este estudio fue analizar las relaciones existentes entre el estilo explicativo, las estrategias de afrontamiento y los síntomas depresivos. El path analysis llevado a cabo con 234 personas mostró que el estilo explicativo negativo (la tendencia a explicar los resultados negativos a través de causas internas, estables y globales) tenía tanto un vínculo directo positivo con los síntomas depresivos como un efecto indirecto a través de las estrategias de afrontamiento evitativo. Además, el estilo explicativo ensalzante (la tendencia a explicar los resultados positivos a través de causas internas, estables y globales) tenía relaciones directas e indirectas de tipo negativo con los síntomas depresivos, solo que en este caso el efecto indirecto se producía a través de las estrategias de resolución de problemas y reestructuración cognitiva positiva y el no uso de estrategias de afrontamiento evitativo. En general, los resultados sugieren que para prevenir la aparición de síntomas depresivos, o para disminuirlos en el caso de que ya existan, se debería promover el estilo explicativo ensalzante y las estrategias de afrontamiento como resolución de problemas y reestructuración cognitiva positiva.

Palabras clave: Estilo explicativo negativo; estilo explicativo ensalzante; síntomas depresivos; resolución de problemas; reestructuración cognitiva positiva; estilo de afrontamiento evitativo.
\end{abstract}

\section{Introduction}

Negative Explanatory Style (NES) is showed when people explain negative situations as arising from causes that are internal (coming from the individual), stable (continuing in the future), and global (applying to lots of different life areas). Attributional reformulation of the learned helplessness theory (Abramsom, Seligman \& Teasdale, 1978) proposed NES as a vulnerability factor for developing depression when people are confronted with stressful situations. Since this proposal many cross-sectional and longitudinal studies have associated NES with depressive symptoms (Lo, Ho \& Hollon, 2010; Rueger \& Malecki, 2011; Sanjuán \& Magallares, 2009; Sanjuán, Magallares, González \& Pérez-García, 2013; Sweeney, Anderson \& Bailey, 1986) and clinical depression (Alloy et al., 2006).

NES research has paid much more attention to relationships between this style and different negative outcomes, such as depression, than to the mechanisms that link this style to those outcomes. However, NES has been suggested to influence negative outcomes through its effect on expectations about future controllability of events (Peterson \& Bossio, 2001). Thus, people with this style would think that nothing can be done to diminish the likelihood of negative

* Dirección para correspondencia [Correspondence address]:

Pilar Sanjuan, Departamento de Personalidad, Evaluacion y Tratamientos Psicologicos, Facultad de Psicología UNED, C/ Juan del Rosal, 10, 28040 Madrid (Spain). E-mail: psanjuan@psi.uned.es
Abstract: The main goal of this study was to analyze the relationships among explanatory styles, coping strategies and depressive symptoms. Path analyses conducted with data of 234 individuals showed that Negative Explanatory Style (tendency to explain negative outcomes through internal, stable, and global causes) had both a positive direct effect on depressive symptoms, and an indirect effect on them through the use of avoidant strategies. On the contrary, Enhancing Explanatory Style (tendency to explain positive outcomes through internal, stable, and global causes) had negative direct and indirect effects on these symptoms, but in this case, the indirect effect occurs through the use of problem solving and positive cognitive restructuring coping and the non-use of avoidant strategies. As a whole, the results suggest that to prevent the onset of depressive symptoms or to reduce them once they appear, enhancing explanatory style and problem solving and positive cognitive restructuring strategies should be promoted.

Key words: Negative explanatory style; enhancing explanatory style; depressive symptoms; problem solving coping; positive cognitive restructuring coping; avoidant coping.

events, and these low expectations would trigger the use of ineffective coping strategies.

Although Enhancing Explanatory Style (EES), which is defined as tendency to explain good results with internal, stable, and global causes, has received very little attention, the results seem to suggest that, unlike NES, it has a protective role on psychological health, since it shows an inverse relationships with depression (Kleiman, Miller \& Riskind, 2012), and a direct relationships with positive outcomes, such as psychological well-being and high self-esteem (Cheng \& Furnham, 2003; Ho, Chan, Yau \& Yeung, 2011).

In relation to EES, no mechanism has been proposed to explain its association with positive results; however, EES could be suggested to present an opposite pattern of associations with coping strategies to that presented by NES. That is, EES would be expected to be positively associated with the use of effective coping strategies.

The effectiveness of coping strategies is a complex issue, which depends on the nature of the stressor, the degree of controllability and duration of the coping process (Lazarus, 1999); however, taking into account the ability of coping strategies to manage psychological distress, research has also shown that coping strategies focused on primary and secondary control are consistently associated with lower psychological distress (Folkman \& Moskowitz, 2000; Stanton, Revenson \& Tennen, 2007). Primary control involves changing the situation (e.g., problem solving, planning), while secondary control involves changing one's own assessments of situations, (e.g., acceptance, positive reappraisal). On the 
other hand, strategies focused on the avoidance of the situation or on emotion intensification are systematically associated with greater psychological distress (Budge \& Adelson, 2013; Folkman \& Moskowitz, 2000; Litman \& Lunsford, 2009; Stanton et al., 2007).

Research on the coping strategies commonly used by people with NES is very scarce; however some studies have shown that NES is inversely associated with the use of coping strategies focused on problem solving (Reilley, Geers, Lindsay, Deronde \& Dember, 2005) and directly linked to the use of avoidant coping strategies (Mikulincer, 1989; Sellers \& Peterson, 1993; Voyce, 1997). So far, we know that NES is positively associated with depression and the use of avoidant coping and negatively related to the use of problem solving strategies. However, whether or not coping strategies are those that mediate the relationship between this style and depressive symptoms would need to be tested. On the other hand, to our knowledge, no study has analyzed the relationships between EES and coping strategies.

Our first goal was to examine the relationships among explanatory styles (NES and EES), coping strategies, and depressive symptoms. In agreement with the evidence and suggestions presented above, we expected NES to be positively associated with depressive symptoms and avoidant coping strategies, and negatively associated with strategies focused on problem solving and positive cognitive restructuring. In relation to EES, we hypothesized that this style would show an opposite pattern of associations, being negatively associated with depressive symptoms and avoidant coping strategies, and positively associated with strategies focused on problem solving and positive cognitive restructuring. Finally, we expected that explanatory styles would indirectly affect depressive symptoms through coping strategies. Taking all these hypotheses into account, the model to be tested can be seen in Figure 1.

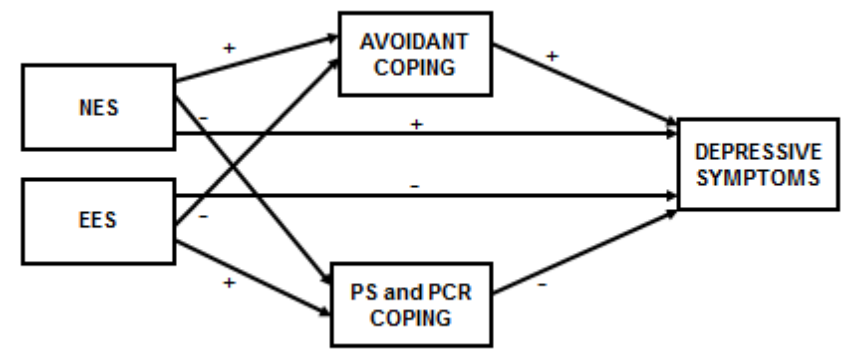

Figure 1. Proposed model on the relationships among explanatory styles, coping strategies and depressive symptoms

Note: NES=Negative Explanatory Style; EES=Enhancing Explanatory Style; PS \& PCR=Problem Solving and Positive Cognitive Restructuring

\section{Method}

\section{Participants}

Two hundred thirty four individuals (103 male and 131 female, mean age $=34.88$ years, Standard Deviation $=9.72$, ranging from 18 to 51) voluntarily participated in the study. Participants were recruited from different workplaces in various urban areas of Spain. On average, the participants had completed 15 years of education. Nineteen $(8.1 \%)$ had finished elementary school, $101(43.2 \%)$ had finished high school, and $114(48.7 \%)$ were holders of a university degree.

\section{Measures and procedure}

All participants were asked to complete the following questionnaires: Attributional Style Questionnaire (ASQ; Peterson et al., 1982 ; Spanish version: Sanjuán, Magallares, González \& Pérez-García, 2013). The ASQ is a self-report instrument containing twelve hypothetical events, six negative and six positive. For each situation, subjects decide what they believe would be the major cause of the event and they indicate on three separate 7-point scales the extent to which they would explain these events with internal, stable, and global causes. A rating of " 1 " on the scales indicates an external, unstable, and specific explanation, while at the other end a "7" reflects an internal, stable, and global explanation.

Two scores, corresponding to attributional style for positive and negative situations, were calculated. These scores were computed by averaging items of positive or negative situations respectively. Higher scores indicate more enhancing and negative explanatory styles respectively. In the current sample, alpha coefficients were .83 and .81 for EES and NES, respectively.

Coping Operations Preference Enquiry (COPE; Carver et al., 1989; Spanish version: Morán, Landero \& González, 2010). This self-report assesses 15 coping strategies through 53 items. Participants were asked to report how often they used these different strategies to cope with different situations in 7 -point scales ranging from " 0 " ("Not at all") to " 6 " ("extremely").

As proposed by different authors (Carver et al., 1989; Litman \& Lunsford, 2009) and in accordance with factors obtained through the exploratory factor analysis conducted with current data, two scores labelled as problem solving and positive cognitive restructuring (PS and PCR) strategies (active coping and planning, suppression of competing activities, positive reinterpretation and growth, and acceptance subscales) and avoidant strategies (denial, focus on and venting of emotions, behavioural and mental disengagement and substance use) were computed by averaging item scores corresponding to the different subscales. Higher scores indicate greater use of these coping strategies. In the current study, alpha coefficients were .85 and .78 for PS and PCR and avoidant strategies respectively.

Depressive Symptoms Subscale of Symptoms Check List Revised (SCL-90-R; Derogatis, 1977; Spanish version: CaparrósCaparrós, Villar-Hoz, Juan-Ferrer \&Viñas-Poch, 2007). This subscale contains 13 items which assess affective, cognitive, and behavioural components of depressive symptoms. Participants were asked to report how strongly they felt these symptoms over the past week in 7-point type Likert scales 
ranging from "0" ("not at all") to "6" ("extremely"). A score was computed by averaging these 13 items, with higher scores reflecting a greater report of depressive symptoms. With current data this subscale obtained an alpha coefficient of .93.

\section{Data analyses}

Firstly we will conduct preliminary analyses to check for possible effects of demographic variables on psychological variables. Specifically, age and education will be correlated with psychological variables. Possible differences between men and women will be analyzed using analysis of variance.

In order to study the relationships between psychological variables, firstly Pearson correlations will be calculated. Subsequently, the predictive power of variables (explanatory styles and coping strategies) on depressive symptoms will be studied using a regression analysis

To test the possibility that coping strategies could be the link between explanatory styles and depressive symptoms, path analysis will be carried out with AMOS software. The significance of direct, indirect and total effects will be assessed using $\chi^{2}$ tests (Kline, 2011). Additionally, well-known and recommended goodness of fit indices will be used to assess the model fit, such as the Root Mean Square Error of Approximation (RMSEA), with values around .05 or lower indicating an adequate fit, and the Comparative Fit Index $(C F I)$, and Normed Fit Index (NFI), with values around .95 or greater indicating an adequate fit (Kline, 2011).

\section{Results}

Age and education did not maintain statistically significant correlations with psychological variables, and therefore those were not taken into account in the following analyses. Although women significantly reported more depressive symptoms [1.78 versus $1.45, F(1,233)=3.95, p<.05]$ and use of avoidant strategies $[2.15$ versus $1.98, F(1,233)=4.53, p<$ .03] than men, the pattern of correlations between analyzed variables was the same among men and women, so the following analyses were carried out with the whole sample.

Correlations between analysed variables for the total sample can be seen in Table 1.

Table 1. Correlations and descriptive statistics.

\begin{tabular}{llllll}
\hline \multicolumn{7}{l}{} & 1 & 2 & 3 & 4 & 5 \\
\hline 1. Depressive symptoms & - & & & & \\
2. NES & $.21^{* * *}$ & - & & & \\
3. EES & $-.31^{* * *}$ & .13 & - & & \\
4. PS and PCR coping & $-.42^{* * *}$ & .03 & $.46^{* * *}$ & - & \\
5. Avoidant coping & $.51^{* * *}$ & $.20^{* *}$ & $-.19^{* *}$ & $-.19^{* *}$ & - \\
Mean & 1.64 & 3.77 & 4.77 & 3.82 & 2.08 \\
SD & 1.24 & 0.76 & 0.71 & 0.69 & 0.61 \\
\hline Note: NES = Negative Explanatory Style; EES $=$ Enhancing Explanatory \\
Style; PS and PCR = Problem Solving and Positive Cognitive Restructuring \\
$* * p<.01 \quad * * * p<.001$ \\
\end{tabular}

As shown in Table 1, depressive symptoms showed significant and positive correlations with NES and avoidant coping, while these symptoms maintained significant and negative correlations with EES and PS and PCR coping. In turn, NES correlated positively and significantly with avoidant coping, while EES was significantly and negatively correlated with avoidant coping and positively with PS and PCR coping.

Can be seen in Table 2, predictor variables together (explanatory styles: NES and EES, and coping strategies: avoidant and PS and PCR coping) explain a significant amount of variance on depressive symptoms $\left[R^{2}=.39\right.$, $F(4,230)=36.9, p<.001]$ and the contribution of each of these predictors is statically significant. Therefore, the inclusion of all of these variables in the model is justified.

Table 2. Regression Analysis to predict depressive symptoms.

\begin{tabular}{llll}
\hline Predictor & $\beta$ & $t$ & Model \\
\hline NES & .15 & $2.88^{* *}$ & $\mathrm{R}^{2}=.39$, \\
EES & -.12 & $-1.96^{*}$ & $F(4,230)=36.9^{* * *}$ \\
PS and PCR coping & -.29 & $-4.98^{* * *}$ & \\
Avoidant coping & .40 & $7.24^{* * *}$ & \\
\hline
\end{tabular}

Note: NES = Negative Explanatory Style; EES = Enhancing Explanatory Style; PS and PCR $=$ Problem Solving and Positive Cognitive Restructuring. $* p<.05 * * p<.01 \quad * * * p<.001$

When proposed model of mediation was tested (see Figure 1), not all indices reached the cut-off criteria $\left[\chi^{2}(1)=\right.$ $3.24, \mathrm{p}=.07$; $C F I=.98 ;$ NFI $=.98 ;$ RMSE $A=.09]$. Moreover, the path between NES and PS and PCR coping was not statistically significant $(t=-0.47, p=.64)$. After this nonsignificant path was removed all the indices indicated a very good fit $\left[\chi^{2}(2)=3.46, \mathrm{p}=.18 ; C F I=.99 ; N F I=.98\right.$; RMSE $A=.05]$. This model is graphically shown in Figure 2.

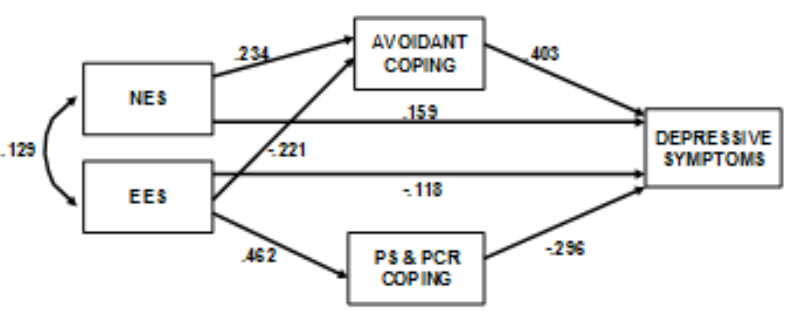

Figure 2. Structural model with standardized regression coefficients $(\beta)$ $[$ All $p$ 's $<.05]$

Note: NES=Negative Explanatory Style; EES=Enhancing Explanatory Style; PS \& PCR=Problem Solving and Positive Cognitive Restructuring

In accordance with this model, NES has both a positive direct effect on depressive symptoms, and an indirect effect on them through the use of avoidant strategies. On the contrary, EES has negative direct and indirect effects on these symptoms, but in this case, the indirect effect occurs through the use of PS and PCR strategies and the non-use of avoidant strategies. 


\section{Discussion}

This study has examined the relationships among explanatory styles (NES and EES), coping strategies and depressive symptoms. As expected, our results show that NES is positively associated with depressive symptoms and avoidant coping strategies. However, this style shows no relation to the strategies focused on problem solving and positive cognitive restructuring. In relation to EES, and as hypothesized, the results show that it is negatively associated with depressive symptoms and avoidant coping strategies, and positively associated with strategies focused on problem solving and positive cognitive restructuring. Finally, our data also support that coping strategies mediate the relationships between explanatory styles and depressive symptoms.

Our results confirm the positive relationship between NES and depressive symptoms found in many previous studies (Lo et al., 2010; Rueger \& Malecki, 2011; Sanjuán \& Magallares, 2009; Sanjuán et al., 2013; Sweeney et al., 1986). This explanatory style is also related to the use of avoidant coping strategies, like some studies had already found (Mikulincer, 1989; Sellers \& Peterson, 1993; Voyce, 1997). Current data also support recent studies that found an inverse relationship between EES and depressive symptoms (Kleiman et al., 2012). As expected, EES is also negatively associated with avoidant coping, and positively related to PS and PCR coping.

Most interesting are the results that show that explanatory styles indirectly affect depressive symptoms through the coping strategies used. In particular, NES had both a positive direct effect on depressive symptoms, and an indirect effect on them through the use of avoidant strategies. On the contrary, the EES had negative direct and indirect effects on these symptoms, but in this case, the indirect effect occurs through the use of PS and PCR coping and the nonuse of avoidant strategies.

These results suggest that coping with stressful situations appears to be influenced by how people interpret and explain events. Thus, people who display a NES, that is, attributing negative events to internal, stable, and global causes, would tend to engage in avoidant coping strategies, which not only impede problem-solving, but also increase emotional distress, like depressive symptoms. On the other hand, people who show an EES, i.e., attributing positive events to internal, stable, and global causes, would tend to engage in PS and PCR coping strategies, while they would not use avoidant strategies, which are associated, in turn, with decreased depressive symptoms.

Our data seem to support that NES, either directly or through its association with the use of avoidant coping strategies, affects psychological well-being adversely (Lo et al., 2010; Rueger \& Malecki, 2011; Sanjuán et al., 2013; Sweeney et al., 1986). By contrast, EES seems to play a protective role in well-being (Cheng \& Furnham, 2003; Ho et al., 2011), either by its direct effect on it or through its association with the use of PS and PCR coping strategies and non-use of avoidant ones. However, the protective role of EES and its relationship with the use of PS and PCR coping strategies should be corroborated in future studies that measure wellbeing in a direct way, since well-being is not merely the absence of negative symptoms like depression.

Some authors have suggested that people with a NES, that is, people who usually explain negative situations by causes that are stable in time, global in effect and internal, have low expectancies on the possibility to diminish the likelihood of negative events (Peterson \& Bossio, 2001), which would lead them to employ ineffective coping strategies. Our study provided evidence that people with a NES report more depressive symptoms and that this may, in part, be due to the use of avoidant coping strategies. Future studies should test whether these low expectancies are mediating variables between NES and the use of ineffective coping strategies. In the same way, they would also have to analyse whether EES is linked with high expectancies on the controllability of events.

Given that depression rates are increasing (WHO, 2011), knowing the different factors which contribute to its onset, development, maintenance, and recovery is of paramount importance. Moreover, converting this knowledge into effective form of treatment and preventive programs would be necessary. According to our results, since EES was negatively associated with depressive symptoms, this explanatory style should be promoted in preventive programs and treatment. Through these interventions people can learn to change their negative attributions for more positive ones, while linking these new explanations to more effective and adaptive coping strategies.

This study was subject to some limitations that deserve mention. Firstly, given that a cross-sectional design was used, the causal role for these explanatory styles can not be established. Although path analysis is a statistical technique that considers hypothetic causal relations between defined variables (Kline, 2011), a statistical procedure can never replace the control of research procedure, and only longitudinal research would clarify the direction of these observed relationships. Thus, with current results we can not know whether explanatory styles are one of the causes of, a consequence of, or even a scar left by depressive symptoms. Future longitudinal research that includes the study of coping strategies could clarify the direction of the relationships between attributional styles and depressive symptoms.

Secondly, though the scales used here are reliable measures widely employed in the literature, self-report measures may be biased (eg. social desirability). Therefore, future studies would improve with a multi-method multimeasure approach.

Despite these limitations, this study provides interesting new data on the role played by coping strategies in the relationships between explanatory styles and depressive symptoms. 


\section{References}

Abramson, L. Y., Seligman, M. E. P. \& Teasdale, D .C. (1978). Learned helplessness in humans: Critique and reformulation. Journal of Abnormal Psychology 87, 49-74.

Alloy, L. B., Abramson, L. Y., Whitehouse, W. G., Hogan, M. E., Panzarella, C. \& Rose, D. T. (2006). Prospective incidence of first onsets and recurrences of depression in individuals at high and low cognitive risk for depression. Journal of Abnormal Psychology 115, 145-156.

Budge, S. \& Adelson, J. (2013). Anxiety and depression in transgender individuals: The roles of transition status, loss, social support, and coping. Journal of Consulting and Clinical Psychology, 81, 545-557.

Caparrós-Caparrós, B., Villar-Hoz, E., Juan-Ferrer, J. \& Viñas-Poch, F. (2007). Symptom Check-List-90-R: fiabilidad, datos normativos y estructura factorial en estudiantes universitarios [Symptom Checklist90-R: Psychometric properties in a representative sample of university students]. International Journal of Clinical and Health Psychology, 7, 781-794.

Carver, C., Scheier, M. \& Weintraub, J. (1989). Assessing coping strategies: a theoretically based approach. Journal of Personality and Social Psychology, 56, 267-283.

Cheng, H. \& Furnham, A. (2003). Attributional style and self-esteem as predictors of psychological well-being. Counselling Psychology Quarterly, 16, 121-130.

Derogatis, L. R. (1977). SCL-90-R, administration, scoring and procedures. Manual for the R(evised) version. Baltimore: Johns Hopkins University, School of Medicine.

Folkman, S. \& Moskowitz, J. (2000). Positive affect and the other side of coping. American Psychologist 55, 647-654.

Ho, S., Chan, M., Yau, T. \& Yeung, R. (2011). Relationships between explanatory styles, posttraumatic growth and posttraumatic stress disorder symptoms among Chinese breast cancer patients. Psychology and Health, 26, 269-285.

Kleiman, E., Miller, A. \& Riskind, J. (2012). Enhancing attributional style as a protective factor in suicide. Journal of Affective Disorders, 143, 236-240.

Kline, R. B. (2011). Principles and practice of Structural Equation Modeling (3th Ed.). New York: Guilford Press.

Lazarus, R. (1999). Stress and Emotion: A new synthesis. New York: Springer.

Litman, J. \& Lunsford, G. (2009). Frequency of use and impact of coping strategies assessed by the COPE Inventory and their relationships to post-event health and well-being. Journal of Health Psychology 14, 982-991.

Lo, C., Ho, S. \& Hollon, S. (2010). The effects of rumination and depressive symptoms on the prediction of negative attributional style among college students. Cognitive Therapy and Research, 34, 116-123.

Mikulincer, M. (1989). Causal attribution, coping strategies, and learned helplessness. Cognitive Therapy and Research, 13, 565-582.
Morán, C., Landero, R. \& González, M. T. (2010). COPE-28: un análisis psicométrico de la versión en español del Brief COPE [COPE-28: A Psychometric Analysis of the Spanish Version of the Brief COPE]. Universitas Psychologica, 9, 543-552.

Peterson, C. \& Bossio, L. M. (2001). Optimism and physical well-being. In E. C. Chang (Ed.), Optimism and pessimism: Implications for theory, research, and practice (pp.: 127-145). Washington, DC: APA.

Peterson, C., Semmel, A., Baeyer, C., Abramson, L.Y., Metalsky, G.I. \& Seligman, M.E.P. (1982). The Attributional Style Questionnaire. Cognitive Therapy and Research, 6, 287-300.

Reilley, S., Geers, A., Lindsay, D., Dereonde, L. \& Dember, W. (2005). Convergence and predictive validity in measures of optimism and pessimism: Sequential studies. Current Psychology, 24, 43-59.

Rueger, S. \& Malecki, C. (2011). Effects of stress, attributional style and perceived parental support on depressive symptoms in early adolescence: A prospective analysis. Journal of Clinical Child and Adolescent Psychology 40, 347-359.

Sanjuán, P. \& Magallares, A. (2009). A longitudinal study of the negative attributional style and attributions of uncontrollability as predictors of depressive symptoms. Personality and Individual Differences 46, 714-718.

Sanjuán, P., Magallares, A., González, J. L. \& Pérez-García, A. (2013). Estudio de la validez de la versión española del cuestionario de estilo atribucional ante situaciones negativas [Study of the validity of the Spanish version of Attributional Style Questionnaire for negative situations]. Revista de Psicopatología y Psicología Clinica (Spanish Journal of Clinical Psychology), 18, 61-71.

Sellers, R. \& Peterson, C. (1993). Attributional style and coping with controllable events by student-athletes. Cognition and Emotion, 7, 431-441.

Stanton, A., Revenson, T. \& Tennen, H. (2007). Health psychology: Psychological adjustment to chronic disease. Annual Review of Psychology 58, 565592.

Sweeney, P. D., Anderson, K. \& Bailey, S. (1986). Attributional style in depression: A meta-analytic review. Journal of Personality and Social Psychology, 50, 974-991.

Voyce, J. (1997). An investigation of the relationships among attributional style, hardiness, gender, and depression as predictors of coping with real life events by chemical dependent inpatients. Dissertation Abstracts International. Section A, 57, 3407.

WHO (2011). Mental health atlas. Geneva: WHO.

(Article received: 25-04-2013; revised: 30-06-2013; accepted: 08-09-2013) 